\title{
Translators' Subjectivity in Commercial Advertising Translation
}

\author{
Yabo Li \\ Western Languages School in Harbin Normal University,Harbin, China \\ ( post code:150026) \\ liyabohsd@sina.com \\ 15046666352
}

\begin{abstract}
Keywords: Economic globalization; Cross-cultural communication; Commercial advertising; Translators' subjectivity; Inter-subjectivity
\end{abstract}

\begin{abstract}
While business interaction and communication between different cultures are increasingly frequent and close, the cross-cultural communication has affected everyone's life more or less. Commercial advertising translation as an effective bridge between Chinese culture and foreign culture is not merely a technique, but an art. Translators' subjectivity plays an important role in promoting products and spreading, affecting, and even innovating their own culture and others simultaneously. Translator's subjectivity is one of inter-subjectivities in translation process; inter-subjectivity is an existing way of subjectivity. Thus, translators' subjectivity study must turn to translating inter-subjectivity study in commercial advertising translation with the development of economic globalization.
\end{abstract}

\section{Introduction}

China has seized the opportunities brought by economic globalization during three decades of political/economic reformation, taking advantage of low labor costs, low raw material costs and other comparative advantages, and implementing the coastal export-oriented development strategy. And so China has quickly become an important commodity manufacturing center of the world, and it's economy overall is the second largest in the world. The goods made in China are being sold in Europe, in America, and around the world. Companies on the platform of the economic globalization are seeking the fortune and profits, using commercial advertising (to become known more widely and gain market share). Hence the translation of commercial advertising between two different cultures is becoming critically important. However, we must truly understand the concept of "the era of globalization" : the economy as a culture to operate; culture is to operate as an economic law, and both sides realize themselves in each other's fields. The United States as the world's largest economic power successfully exported the biggest cultural commodity-America's image around the world. Culture as an important part of the country's comprehensive national strength must be kept in sync with the economic development and advancement, which can lead the country towards a healthy (and integrated) direction. Commercial Ads translation can maximize economic benefits, improve understanding and communication between different cultures or different ethnic groups, and enrich the cultural life of humanity. English commercial advertising translated into Chinese succeeded in getting Chinese people to learn more about the world's major brands, and understand cultures throughout the world. Similarly, Chinese commercial advertising translation not only promotes Chinese goods to the world, but also gets the whole world to understand China and Chinese culture. The English translation of Chinese commercial advertising should not only conform to the needs of the times, but also helps China to build and establish brands and corporate images. Such cultural and economic activities will span cultural identity and consensus like an invisible bond, bringing people of different cultures together to promote world peace and stability. 


\section{Translators' Subjectivity of Commercial Advertising in the Economic Globalization Era}

Definition of subjectivity should begin from the self-awareness campaign caused by French philosopher Descartes' "Cogito ergo sum" (I think, therefore I am). From a philosophical perspective to define the subjectivity: "Referring to the person as a provision of the subject, the most fundamental contents of human subjectivity is practical ability and creativity" (Zhang, Quan, 2010: 165). The subjectivity should refer to the person's subjective initiative ("it is a theory of exploring the meaning of understanding and interpretation") including the person's purpose, autonomy, creativity, and so on. Subjectivity highlights the humanity, which is the source and destination of all human thinking activities. Subjectivity as the self-consciousness activity of humans, of course, covers a wider area: such as religion, art, will, morality, emotion, expressions of sub-consciousness, and so on. The translator's subjectivity can be summarized as follows: Translating subject should fully respect the translating object, then show his subjective initiative for successful and effective communication and exchange purposes. Basic features of the translator's subjectivity are translators' humanistic spirit, cultural awareness, cultural creativity, and aesthetic creativity.

\section{Inevitable Creative Treason}

French sociologist Robert Escarpit in his book "Literary Sociology" firstly introduces the concept of "creative treason". "The translation is treason, because it placed a piece of work in a totally unexpected reference system (of language); translation is creative, because it gives the work a new look which makes it possible to carry out a new literary exchanges with a wider audience; and it not only extends the life of the work, but also it gives a second life to the works. "(Robert Escarpit, 1987: 137). Robert pointed to the translator's dynamic role in the process of translation: creativity and rebellion. Translators, through personal understanding and interpretation, create a new text to show the charm of the original text, attempting to do this vividly and skillfully. Translators firstly are the original text's readers, then the original text's interpreters, and finally a new text's creators, so translators are the most active factors in translation practice.

Translation is one of the most complex tasks. Advertising translation will not only involve the conversion of two basic elements of sign language, cultural values, and aesthetic standards, but also involve the business environment in different countries or regions, market demands, customer psychology, religious taboos (or devotions), political ideology, and other factors. "Translation effects have close relationship with the recipients and the receiving environment. Something may be positive in the context of source language environment, but it actually becomes a negative in the target language environment; and vice verse. It is the translation's creative treason to the recipients and to the receiving environment "(Xie, Tianzhen, 1999: 164). Mr. Xie's view showed us the difficult situation of the translator. In order to meet the need of target language readers and target language environment, the translators must have the vision and talent of military strategists. Sometimes translators retreat in order to go forward and go ahead in order to retreat, when they are in a dilemma position.

\section{Subjective Treason}

"Subjective treason" is the creative treason caused by translators' subjective reasons. American anthropologist and linguist Sapir - Whorf's hypothesis is the inheritance and development of Humboldt's view of language. "Literature in a language of form and material form always has its mold of colors and lines. Literary artists may never feel the mold is how it affects, hinders, helps, or guides them in other ways, but as soon as his works are translated into other languages, the original characteristics of the mold soon will be revealed (Sapir, 2003: 15). The language people use has a profound impact on the recipients' ways of thinking, shapes people's minds, and plans, and guides their psychological activities. Similarly, in the long-term language translation practice, translators will gradually accumulate a lot of successful experiences or failures, and form a unique concept of 
translation theory and translation practice. For example: Yan Fu's "faithfulness, expressiveness, and elegance"; Lu, Xun's "Faithfulness is more important than expressiveness"; Lin, Yutang's "being faithful, fluent, and beautiful"; Qian, Zhongshu's "Transformation"; Eugene Nida's "functional equivalence"; Peter Newmark's "communicative translation and semantic translation"=, and so on are different translation theories and translation principles, but the concept of translation theory will always influence translator's practice, therefore the "subjective treason" will appear.

Translators will inevitably be subjective in interpretation of the source language works. These personal subjective factors include: translator's value criteria, translator's knowledge, translator's life experience, translator's art appreciation, and aesthetic appeal. That is why, for the same piece, different translators will have different interpretations, and different readers will have different understandings, which is reflected in the creation of translation is a creative treason. For example: America's global express delivery company UPS' advertising:

"We care to provide service above and beyond the call of duty." (UPS)

Translation1: 我们愿意提供高于或超出责任感的服务(We are willing to provide services above or beyond the responsibility.)。( UPS 快递)

Translation2: 殷勤有加，风雨不改(Attentive and on time without any reason)( UPS 快递)。

Obviously, the disadvantage of first translation is too rigid, despite of being faithful to the original slogan's semantics, meaning and sentence structure, but (or: yet) fails to successfully express the advertising's purpose and has a big gap with the original slogan in publicity. As we all know, the purpose of advertising is to positively promote the image of enterprises or institutions, to attract more consumers with the direct and effective way, and to get target language readers eager to read and understand the advertising. The second UPS translation above will better realize the purpose of advertising translation. The translator fully digests the contents of the original text and understands the spirit of the original text. Hence, the translator can adeptly and boldly transforms the original text using a method of creative treason to show the advertising language's powerful induction. At the same time the translator conforms to the Chinese characteristics using a four word structure in advertising.

In Chinese Advertisements translated into English, translators "should do expansion, choice, concentration, interpretation, supplement, transformation in original center or part content in accordance with the special demands of target readers" (Huang, Zhonglian, 2002: P68- 69). For example: Tianjin famous food “狗不理” dumplings (The creator's nick name was “ dog”. His dumplings were very popular, and many customers came to his restaurant everyday. Some old friends also came and talked to the owner who had no time to chat with them, so people had a joke to say: "The dog is too busy to respond.") As the old brand of traditional Chinese culture, it is translated to "Go Believe". Although English "Go Believe" has no association with Chinese "Gou Buli" in literal sense, the English pronunciation fit with "Gou Buli", and the translator uses the verb "Go" in the imperative form to reach persuasion function. The other word "believe" also expresses exquisite craftsmanship of the dumplings with elegant materials and delicious taste worthy of being trusted. The translator fully uses subjectivity creatively to endow to the original text a second life.

\section{Objective Treason}

Objectivity treason means translator is affected by objective factors in the translation process. Advertising Translation has all the characteristics of creative advertising, but also is restricted by the constraints of commercial advertising including advertising regulations, market rules, marketing strategies, and other cultural barriers. Advertising regulation is the factor that must be considered firstly by translators. In addition, the translator must also consider the social and cultural background of the readers, consumer psychology, the level of education, purchasing power, and other factors. In order to cater to the various needs of target readers, translators may use objective treason to translate.

In order to create a worldwide tourism brand and attract more foreign tourists, Guilin city government and Translators Association of China jointly held a press conference on April 14, 2005 
to collect the best English translation of this tourism advertising slogan:“桂林山水甲天下” (Guilin's mountains and waters are the finest in the world). In the end the English translation of "East or west, Guilin's scenery is the best." took first place. The reason is easy to see, although the translator gave up the meaning of words and sentences for Chinese faithfulness, the new translation skillfully uses the English-speaking people's familiar proverb - "East or west, home is the best" to convey the Chinese slogan. Such translation not only expresses people's high evaluation of Guilin flexibly and vividly, but also makes this slogan easily understood and accepted by English readers.

\section{Translators' Subjectivity to Translating Inter-subjectivity}

There is no doubt of translator's subjectivity in the advertising translation process, but it is not isolated, and it co-exists with the creator's subjectivity of original text, and the subjectivity of target readers. The advertising translation process is the result of mutual cooperation, equal dialogue, positive interaction, coordinate operations, and concerted action among various subjects. Mr. Mao Dun had done the exposition: "This translation is not a simple technical change from language form, but requires the translator's deep appreciation of the author's artistic creativity process. Translators should grasp the spirit of the original text, and find out the most suitable counterpart in their own thoughts, feelings, and life experience. Then translators use the appropriate literature language to present and express the original content and form correctly. Translator and author will become one person in such translation process, as if the original author is writing his own work in a foreign language "(Mao Dun, 1984: 10). Commercial translation processes are actually processes of dialogue among subjects. Such dialogue needs multi-agents involved with the rapid development of communicative and scientific technology. The dialogue among subjects is bound to be inter-subjective. According to the definition of communicative action Habermas gave: "The communicative action is used to disseminate and update cultural knowledge", "Communicative action creates a solidarity function", "Communicative action is to create a personal characteristics and nature (Habermas, 1989:571)." Habermas believes reasonable and effective interaction among subjects mainly promotes the true understanding between self and otherness, and it really spreads the advanced achievements of human civilization. Advertising translation itself is cross-cultural communicative behavior among different subjects.

\section{Conclusion}

In the $21^{\text {st }}$ century, advertising translation process must be completed by group effort. It is a mutual understanding process, mutual respect process, and mutual acceptance process. It is an equal dialogue and equal exchange among subjects. Successful advertising translation practice is not contrary to traditional translation thoughts and does not resist the faithfulness to the original text and the original author's intent, but does not depart from post-modern translation ideas which emphasizes and makes transparent the translator's subjectivity. Advertising translation should absorb and inherit the essence of both, and go forward smoothly in constant reflection and experience. As an initial advertising readers, translators should fully understand and respect the original intent of advertising designers, agree on the advertising sponsors' interests, and understand the positions of target readers to adopt a variety of translating strategies and methods to convey the original advertising's charm and purposes. Wittgenstein often likes to describe language as tools, and language activities as a game. Advertising translation is an activity played by author, translator, and readers with various tools to measure, to repair, and to transform an old machine. The purpose of this activity is to create a new machine in accordance with the rules in advance and even with a new game's rules. In summation, within the context of globalization and cultural exchanges, the translator's subjectivity necessarily goes to inter-subjectivity in commercial advertising translation process, and can be a "Make or break deal" for the initiating organization. 


\section{Acknowledgements}

Thirteenth Five-Year Planning Project: Heilongjiang Province Education Science Planning Project in 2016 (GJC1316100)

\section{References}

[1] Escarpit, Robert. Sociological Literature [M]. translated by Wang, Meihua \& Yu, Pei. Hefei: Anhui Literature and Art Publishing House, 1987.

[2] E.Sapir. Language Theory [M]. translated by Lu, Zhuoyuan. Beijing:Commercial Press, 2003.

[3] Habermas. Exchanges and Social Evolution[M]. translated by Zhang, Boshu. Chongqing: Chongqing Publishing House, 1989.

[4] Huang, Zhonglian. Variation Theory [M]. Beijing: China Translation and Publishing Corporation, 2002.

[5] Kong, Emily. Translation, Literary, and Culture [M]. Beijing: Peking University Press, 1999.

[6] Li, Zhigang. Advertising Principles and Practice [M]. Chongqing: Chongqing University Press, 2004.

[7] Mao, Dun. The struggle to Improve Translation Quality and to Develop Literary Translation Career [A] Translation Research Papers (1949-1983) [C]. Beijing: Foreign Language Teaching and Research Press, 1984.

[8] Tu, Jiliang. editor of "The Complete Works of Wittgenstein" VIII "Philosophical Investigations" [M]. translated by Tu, Jiliang .Shijiazhuang: Hebei Education Press, 2003.

[9] Xie, Tianzhe. Translation Studies[M]. Shanghai: Foreign Language Education Press, 1999.

[10]Zhang, Quan. Intercultural Translation Studies from Globalization Perspective[M] Kunming: Yunnan University Press, 2010. 